\title{
LA JUSTICIA DISTRIBUTIVA ARISTOTÉLICA EN EL SIGLO XXI
}

\author{
Juan Ramón LiÉBANA ORTIZ
}

DOCTOR EN DERECHO

DOCTORANDO EN FILOSOFÍA POR LA UNIVERSIDAD AUTÓNOMA DE MADRID

juanramon.liebana@unir.net

SUMARIO: I. INTRODUCCIÓN. II. LOS SISTEMAS TRADICIONALES DE JUSTICIA INFORMAL. III. LA JUSTICIA INFORMAL TRADICIONAL COMO JUSTICIA DISTRIBUTIVA ARISTOTÉLICA. IV. JUSTICIA INFORMAL TRADICIONAL, ESTADO DE DERECHO Y DERECHOS HuMANOS. V. BIBLIOGRAFÍA.

RESUMEN: La comunicación presenta los sistemas tradicionales de justicia informal como un ejemplo donde se constata cómo la doctrina aristotélica sobre la justicia distributiva permite justificar teleológicamente la existencia de modelos judiciales diferentes a los sistemas procesales estatales de corte liberal que, en pleno siglo XXI, aplican ordinariamente los principios esenciales del Derecho natural.

PALABRAS CLAVE: Justicia informal tradicional, justicia distributiva aristotélica, Estado de Derecho, Derechos Humanos.

\section{ARISTOTLE'S THEORY OF DISTRIBUTIVE JUSTICE IN THE $21^{\text {sT }}$ CENTURY}

ABSTRACT: This paper presents the traditional informal justice systems as an example where it can be seen how the Aristotelian doctrine on distributive justice allows to teleologically justify the existence of different judicial models to the liberal State procedural systems which in the 21 st Century ordinarily apply the essential principles of natural Law.

KEYWORDS: Traditional informal justice systems, Aristotelian distributive justice, Rule of Law, Human Rights. 


\section{Introducción}

El reconocimiento de la igualdad y libertad como derechos inalienables del hombre en el constitucionalismo contemporáneo tiene una consecuencia inmediata: la transformación de unos principios filosóficos en mandatos jurídicos. El concepto de Derechos Humanos es una noción iusfilosófica: la de que ciertos derechos son necesarios para que se pueda hablar de ser humano, y de dignidad humana. Pero el reconocimiento jurídico de estos derechos los convierte en mandatos vinculantes, que no dependen de las convicciones de cada uno. Los Derechos Humanos se convierten en derechos fundamentales. Se pasa, así, de un concepto iusnaturalista a un concepto iuspositivista. Pero ha de recordarse que incluso los textos constituciones, en muchos casos, proclaman que la regulación y definición de los derechos que llevan a cabo se realiza en virtud de la convicción de que, efectivamente, esos derechos y libertades son anteriores y superiores a la propia Constitución. La teoría de los derechos fundamentales sostiene que la Constitución les da valor jurídico, pero reconoce su valor moral propio.

En todo caso, esta justificación ética de los derechos fundamentales no obsta a su carácter jurídico: son derechos fundamentales porque, por voluntad del poder constituyente, están recogidos como tales en la Constitución. Por este motivo, aun cuando existan unas bases iusfilosóficas comunes para definir qué sea un derecho fundamental, la determinación, en cada Estado, de cuáles son esos derechos reconocidos constitucionalmente como tales dependerá de las previsiones concretas contenidas en la Constitución y en su desarrollo legislativo.

Ahora bien, esta aproximación a los derechos humanos suponer una visualización a la humanidad como sujeto de Derecho desde la óptica del Estado. Una perspectiva que resulta miope cuando se estima que al principio del segundo milenio más del ochenta por ciento de los conflictos son resueltos a través de diversos sistemas de justicia informal en algunos países ${ }^{1}$.

Los sistemas de justicia informal son mecanismos para la resolución de conflictos que no forman parte de los sistemas judiciales estatales y que, aunque no son muy comunes ni en Europa ni en Estados Unidos de América, están ampliamente extendidos en los países del hemisferio sur, donde abordan cuestiones de gran trascendencia jurídica tanto para las personas como para las comunidades en donde ejercen su jurisdicción (como, por ejemplo, conflictos familiares, sobre la propiedad o incluso los delitos menores).

Sin embargo, la crítica principal que de ordinario se realiza de estos sistemas de resolución de conflictos es que las estructuras de los sistemas de justicia informal y los Derechos consuetudinarios que suelen aplicar resultan incompatibles con el respeto a los principios del Estado de Derecho y de los Derechos Humanos. No se tiene en cuenta, por consiguiente, que desempeñan un importante papel en el mantenimiento de la paz social en las comunidades rurales, y resultan vitales para garantizar el acceso a la justicia de millones personas.

Este trabajo propone una nueva mirada a los sistemas tradiciones de justicia informal, poniendo el acento precisamente en los límites del Estado de Derecho desde la óptica de la Humanidad, para, a través de la teoría de la justicia distributiva aristotélica, proponer una serie de estrategias que permitan promover sociedades justas, pacíficas e inclusivas; contribuyendo así a la consecución de unos objetivos de Desarrollo Sostenible promovidos por la Organización de Naciones Unidas para transformar nuestro mundo con el horizonte temporal de 2030.

\footnotetext{
${ }^{1}$ Danish Institute for Human Rights, Informal Justice Systems: Charting a Course for Human Rights Based Engagement, (United Nations Entity for Gender Equality and the Empowerment of Women, New York 2013), p. 7.
} 


\section{Los sistemas tradicionales de justicia informal}

Los sistemas tradicionales de justicia informal juegan un papel muy importante en la resolución cotidiana de los conflictos jurídicos y en el mantenimiento del orden y la paz social en comunidades rurales de los cinco continentes del mundo, aunque resultan especialmente relevantes en los países con un marcado pasado colonial en donde el pluralismo jurídico tiene una presencia muy destacada.

En efecto, en muchos países con pasado colonial las instituciones judiciales estatales (Tribunales, jueces, abogados, Ministerios de Justicia, policía y prisiones) operan junto con sistemas tradicionales de justicia informal, que han sido parte integral de los ordenamientos jurídicos y organizaciones sociales indígenas desde mucho antes de la llegada del Estado moderno ${ }^{2}$. También en España perviven algunos Tribunales consuetudinarios y tradicionales (el Tribunal de las Aguas de Valencia, el Tribunal del o el Consejo de los Hombres Buenos de Murcia, por ejemplo) con un expreso reconocimiento constitucional y legislativo, aun a pesar de no respetar in toto los principios esenciales del Estado de Derecho en su procedimiento judicial.

Estos sistemas tradicionales de resolución informal de conflictos no han desaparecido con el empuje cumulativo de la modernidad y de la globalización, o de haberse convertido en Estados independientes los territorios en donde coexistían con los ordenamientos jurídicos coloniales. Por el contrario, la justicia informal tradicional ha demostrado ser extraordinariamente resiliente ya que ha sabido adaptarse a las dinámicas locales y externas del cambio social. A este respecto, el término "tradicional" resulta engañoso en la medida en que implica que la justicia "tradicional" es un fenómeno fijo y cierto, que se ha mantenido sin cambios desde tiempos inmemoriales. La realidad es que los sistemas tradicionales de justicia informal son fluidos y dinámicos, y se adapta constantemente al cambio. Sólo así se puede explicar su pervivencia secular contra viento y marea, lo que además nos permite ser optimistas sobre el futuro de la justicia informal tradicional en el sentido de que esa capacidad de adaptación permitirá conseguir integrar en ellos los estándares mínimos de Derecho Internacional de los Derechos Humanos para que no resulten grotescos en las sociedades del siglo XXI.

Con carácter general se puede decir que todos los sistemas tradicionales de justicia informal suponen un sistema ancestral de conciliación, mediación y arbitraje de los que se pueden constatar diversas fortalezas y debilidades respecto a las jurisdicciones ordinarias dependientes de los sistemas procesales estatales.

Las fortalezas de los sistemas tradicionales de justicia informal son su accesibilidad, asequibilidad, inmediatez, legitimidad y efectividad dentro de sus respectivas comunidades locales, el uso de idiomas y dialectos locales, la comprensión de las posturas divergentes de las partes, la promoción de relaciones familiares sólidas, las sanciones basadas en indemnizaciones y su eficacia para poner fin a las disputas y promover la reconciliación de las partes por el bien de la sociedad en su conjunto.

\footnotetext{
2 Son muchos los ejemplos de sistemas tradicionales de justicia informal existentes en el mundo. A modo de ejemplo, podemos citar los tribunales comunitarios de Ruanda (Gacaca) o Mozambique (Tribunales populares), los Tribunales de Aldea indios (Gram Nyayalayas) y bangladesíes (Shalish), los Jirgas pakistaníes, las comunidades rurales indígenas en Perú (Calahuyo) y Colombia (Paez) o la justicia informal tradicional en Oceanía (Kastom o Adat). Para su análisis pausado cfr. LiÉBANA OrTIZ, J. R., Los sistemas tradicionales de justicia informal en el siglo XXI, (Thomson Reuter Civitas, Cizur Menor 2018), passim, especialmente pp. 41-78.
} 
Ahora bien, los sistemas tradicionales de justicia informal también presentan una serie de deficiencias: la ausencia de garantías procesales contra las violaciones de los Derechos Humanos, especialmente de mujeres y niños, la parcialidad de los jueces informales e inconsistencias y falta de certeza en su toma de decisiones, la aplicación limitada de sus sentencias por la fuerza de la conformidad social o la falta de equidad respecto de clases particulares de personas como son mujeres, niños o minorías étnicas y/o religiosas de las comunidades donde extienden su jurisdicción.

En consecuencia, cabe concluir que los sistemas tradicionales de justicia informal no son perfectos. Los procedimientos informales se han desarrollado al margen de la legalidad estatal, ya que se basan exclusivamente en las tradiciones y el Derecho consuetudinario tal y como es interpretado por la auctoritas de los jueces informales, y por lo tanto sin una estricta observancia de los principios informadores del Estado de Derecho. Igualmente, con sus sentencias los sistemas tradicionales de justicia informal pueden consagrar determinados valores y prácticas subyacentes que contribuyan a que los grupos vulnerables de la comunidad en cuestión vean conculcados sus derechos, y ello para hacer cumplir las tradiciones y costumbres de la comunidad ${ }^{3}$. Así, aunque es cierto que existen ejemplos (como el de la justicia indígena colombiana) en donde estos sistemas tradicionales de justicia informal funcionan razonablemente bien, en muchos contextos la calidad de la justicia informal tradicional es incompatible con los estándares mínimos de Derecho Internacional de los Derechos Humanos.

Resulta erróneo el planteamiento de estrategias para introducir o fortalecer los principios del Estado de Derecho y promover los Derechos Humanos en los sistemas tradicionales de justicia informal desde la visualización de la humanidad como sujeto de Derecho desde la óptica del Estado, y centrándose en consecuencia exclusivamente en la justicia formal estatal, puesto que en la práctica la inmensa mayoría de los conflictos jurídicos que se producen en el ámbito rural son resueltos por la justicia informal tradicional4: la popularidad de los sistemas tradicionales de justicia informal incluso en aquellos casos en que el Estado niega su legitimidad- se debe en parte a las deficiencias (o a la falta de legitimidad) del sistema de justicia formal; pero también refleja el valor otorgado por la población a los enfoques tradicionales en la resolución de conflictos.

Consideramos que todos los sistemas de justicia informal deben cumplir unos estándares mínimos de Derechos Humanos: a) aplicar sanciones acordes con la naturaleza y la importancia del litigio en cuestión, y que sean consistentes con las disposiciones constitucionales sobre derechos fundamentales; b) proscribir los castigos físicos y las condenas que supongan un trato inhumano o degradante dentro de la comunidad; c) evitar el enjuiciamiento informal de delitos graves tales como el asesinato o las agresiones y abusos sexuales; y d) establecer áreas de complementariedad entre los sistemas tradicionales de justicia informal y los sistemas jurisdiccionales estatales. Se trata simplemente de que los sistemas tradicionales de justicia informal respeten los deberes naturales universales en cuanto que sus procedimientos y resoluciones se dirigen contra y afectan a los seres humanos en cuanto tales.

\footnotetext{
${ }^{3}$ Para una caracterización de los principios procesales de la justicia informal tradicional vid. LIÉBANA ORTIZ, J. R., op. cit., pp. 82-97.

${ }^{4}$ Debe recordarse, además, que en determinados supuestos la falta de reconocimiento de los sistemas de justicia informal tradicional puede ser discriminatoria en sí misma ya que, en muchos casos, son un componente central de la identidad individual y colectiva y la dignidad de las poblaciones indígenas a las que se aplican. Así, de acuerdo con el Convenio núm. 169 sobre pueblos indígenas y tribales adoptado por la Organización Internacional del Trabajo en Ginebra el 29 de junio de 1989, los pueblos indígenas tienen un derecho colectivo a un cierto grado de autonomía normativa e institucional.
} 
Se trata, en fin, de llevar al ámbito del enjuiciamiento de la justicia informal tradicional los principios esenciales del iusnaturalismo: 1) Que, además, y por encima del Derecho consuetudinario (de la ley humana) existe un Derecho natural, esto es, un conjunto de normas y/o principios válidos para todos los tiempos y lugares. 2) Que el Derecho (positivo) sólo es tal si concuerda (al menos en sus principios fundamentales) con el Derecho natural, es decir si es justo. En otro caso, no pasa de ser "apariencia de Derecho" o "corrupción de ley".

\section{La justicia informal tradicional como justicia distributiva aristotélica}

El problema fundamental que plantean los sistemas tradicionales de justicia informal respecto de los principios del Estado de Derecho tiene que ver con el choque de las concepciones tribales y comunitarias de las sociedades rurales en donde fundamentalmente se encuentran vigentes los sistemas tradicionales de justicia informal con el pensamiento político liberal imperante en la actualidad: la idea de que la justicia debe ser neutral con respecto a las distintas concepciones de la vida debido a que la persona es un ser que, en sí mismo, carece de ataduras morales previas y escoge con libertad.

La gran virtualidad de las teorías de la justicia que aspiran a la neutralidad es que ofrecen la esperanza de que los sistemas judiciales quedan liberados en su aplicación del Derecho de las controversias morales y religiosas que abundan en las sociedades en donde existe un arraigado pluralismo jurídico. De esta forma, ni la costumbre, ni la tradición se heredan: la fuente de las únicas obligaciones morales que nos ligan es la libre elección de cada individuo. Concebir a una persona como un ser en sí mismo libre e independiente de la comunidad no sólo hace que se vea de manera distinta la responsabilidad colectiva entre las generaciones, sino que también implica que los principios de la justicia que definen los derechos individuales no deben descansar sobre ninguna concepción moral o religiosa particular, sino que, por el contrario, deben ser neutrales entre las diferentes cosmovisiones existentes en las sociedades plurales.

El punto de vista individualista de la libertad se encuentra ínsito no sólo en el pensamiento político liberal imperante en occidente, sino también en las teorías modernas de la justicia. El pensamiento contemporáneo asocia la promoción estatal de determinados ideales morales con los fundamentalismos religiosos, lo que deriva en apedreamientos de adúlteras, burkas obligatorios so pena de largas penas de prisión, etc., es decir, una justicia contraria a los Derechos Humanos.

Ahora bien, los datos estadísticos muestran que en muchas zonas rurales del planeta se prefieren los sistemas tradicionales de justicia informal a los sistemas jurisdiccionales estatales de corte liberal occidental ${ }^{5}$. Debe tenerse en cuenta, además, que la preferencia generalizada en estos

\footnotetext{
${ }^{5}$ Así, si nos centramos en África, comprobamos que en Malawi entre el $80 \%$ y el $90 \%$ de los conflictos son resueltos por Tribunales informales tradicionales. En Bangladés entre el 60\% y el $70 \%$ de los conflictos surgidos a nivel local son resueltos por Shalish. En Sierra Leona el $85 \%$ de la población se rige por el Derecho consuetudinario que aplican los sistemas tradicionales de justicia informal de las distintas comunidades rurales. En torno al $80 \%$ de los burundeses resuelven sus conflictos jurídicos en primera, y a veces única instancia, ante el Bashingantahe en vez de ante los tribunales ordinarios estatales. Las normas consuetudinarias sobre tenencia de la tierra se aplican al 75\% de la tierra en la mayoría de los países africanos, y el $90 \%$ de los conflictos sobre las transacciones de tierras en países como Mozambique y Ghana se resuelven a través de Tribunales informales tradicionales. Vid., en este sentido, Chirayath, L., SAGE, C. y WoOlCoCK, M, Customary Law and Policy Reform: Engaging with the Plurality of Justice Systems, (World Bank, Washington 2005), p. 3.
} 
contextos por la justicia informal tradicional resulta en todo caso de una decisión racional de los individuos que viven en las comunidades rurales y a los que afecta la justicia informal tradicional.

Ante esta realidad, debemos cuestionarnos las bondades prácticas de la universalización del dogma liberal de la justicia a la vez que nos planteamos los posibles beneficios del empoderamiento a la justicia informal tradicional para que contribuya igualmente con su particular cosmovisión de la justicia en la construcción de un Derecho global que ha de responder también a las complejidades de las realidades diversas que enfrentan en su día a día millones de personas que viven en el entorno rural, y a las que la justicia liberal imperante entre la élite global les resulta totalmente ajena.

La justicia material no sólo exige un conjunto de valores abstractos, sino que también debe comprender las relaciones concretas de causa-efecto. Ello resulta particularmente evidente en las comunidades rurales en donde operan los distintos sistemas tradicionales de justicia informal que hemos analizado en el presente trabajo, lo que permite sostener la modulación de los principios que rigen del Estado de Derecho en función de las tradiciones ancestrales comúnmente aceptadas de las comunidades rurales. Ello no obsta para que todos los sistemas tradicionales de justicia informal deban cumplir los estándares mínimos del Derecho Internacional de los Derechos Humanos. Por ello conviene analizar el fenómeno de la justicia informal tradicional desde la perspectiva de la Filosofía moral.

Así, cabe recordar que los sistemas tradicionales de justicia informal -cuyo objetivo al hacer justicia es la restauración de la paz y la armonía social dentro de la comunidad, asegurándose además de que las partes en conflicto y sus respectivos clanes familiares se reconcilien- tienden a existir en pequeñas comunidades rurales, dominadas por relaciones múltiples, en donde un conflicto entre dos miembros de la comunidad se considera un problema que afecta a toda la comunidad, por lo que las sanciones impuestas por el tribunal informal tradicional son eminentemente restaurativas y su cumplimiento se garantiza mediante la presión social.

De esta forma, la pertenencia de una persona a una determinada comunidad o grupo social coincide con la intensidad y proximidad de sus vínculos en ella, y el sentimiento de pertenencia a la comunidad conlleva la responsabilidad moral de aceptar las sentencias dictadas por el Tribunal informal tradicional y de cumplir voluntariamente las sanciones impuestas por éste. Debe tenerse en cuenta que una de las características distintivas de la justicia informal tradicional es que con ella se pretende que las persona que han transgredido el Derecho consuetudinario sientan vergüenza frente a la comunidad y frente a las personas que han dañado y que, por virtud de ese sentimiento negativo, no vuelvan a reincidir o a cometer otra infracción que dañe a algún otro miembro del grupo social y, por ende, a la comunidad.

La facultad de sentir vergüenza por los actos de los parientes y de otros miembros de la comunidad guarda relación con la facultad de sentir una responsabilidad colectiva. La ética de la responsabilidad colectiva se encuentra en estrecha relación con la ética de la vergüenza: ambas requieren que se exteriorice que lo que uno mismo es tiene un contexto, que está sometido a las exigencias de lazos morales que no ha escogido, que forma parte y está vinculado por las tradiciones y costumbres de la comunidad que moldean la identidad de los individuos en cuanto agentes morales. En este sentido cabe recordar, con Rousseau ${ }^{6}$, que el apego y las identidades comunitarias son

${ }^{6}$ Cfr. Rousseau, J. J., Discurso sobre la economía política (trad. y ed. Vélez, F.), (Maia, Madrid 2011), pp. 48-49: "Parece que el sentimiento humano se evapora y debilita cuando se reparte por toda la Tierra, de modo que nos afectan menos las calamidades de Tartaria o del Japón que las de un pueblo europeo. En cierta forma, es preciso limitar y reducir el interés y la conmiseración para poder activarlos. Ahora bien, como quiera que esa tendencia sólo beneficia a quienes con nosotros conviven, es bueno que la humanidad concentrada entre 
complementos necesarios de nuestra humanidad universal, de tal manera que sólo si la pertenencia del individuo a la comunidad tiene algún fundamento moral, sólo si la cohesión comunitaria conduce a obligaciones y significados compartidos que distinguen entre miembros de la comunidad y extraños a la misma, tendrán alguna razón los líderes locales, tribales o religiosos de una determinada comunidad rural para ocuparse en especial del bienestar de su propio pueblo y de la pervivencia y éxito de su propia cultura a través de su respectivo sistema tradicional de justicia informal que, con sus resoluciones, busca la restauración de la paz y la armonía social dentro de la comunidad cuando éstas han sido perturbadas con el surgimiento de un conflicto entre algunos de sus miembros?

También podemos analizar desde la óptica de la Filosofía moral otra de las características de los sistemas tradicionales de justicia informal, a saber: ¿Cómo se explica que, tras el cumplimiento de la sanción impuesta, el condenado celebre un acto festivo o un ritual religioso de agradecimiento al ofendido en el que se coma o se brinde con todos los que han intervenido en el procedimiento informal tradicional? Expresado en otros términos, ¿cómo es posible que se reconozca el peso moral de la comunidad sin coartar la libertad individual? Porque el aspecto teleológico de la reflexión moral está ligado a la adscripción del individuo a la comunidad: la historia vital de los individuos está siempre íntimamente ligada a la comunidad a la que pertenecen, de tal forma que si el condenado se desliga de las tradiciones y costumbres que ha interpretado el Tribunal informal tradicional para emitir su sanción restaurativa de la armonía social y, en consecuencia, decide individualmente incumplir la condena impuesta por toda la comunidad, que ha tenido la oportunidad de participar activamente en el procedimiento informal, la consecuencia es que se deforman las relaciones sociales presentes y futuras del condenado en la comunidad ${ }^{8}$. En la práctica ello puede conllevar su ostracismo social, de tal forma que se le deniegue el acceso al mercado laboral, cooperación económica, participación en las actividades y fiestas de la comunidad, etc.

Por consiguiente, los sistemas tradicionales de justicia informal no pueden entenderse desde la concepción liberal de la justicia, porque ésta requiere que se respeten los derechos individuales de las personas y que no se fomenten los valores morales que cada concreta sociedad considere ideales. Según la concepción liberal de la justicia ${ }^{9}$, sólo pueden surgir obligaciones morales para las personas de dos maneras: como un deber natural ante los seres humanos en cuanto tales, y como una obligación

conciudadanos adquiera en ellos una fuerza renovada gracias al hábito de verse y al interés común que los reúne".

${ }^{7}$ En igual sentido, vid. WALZER, M., Spheres of Justice, (Basic Books, New York 1983), pp. 37-38.

8 Así, MacIntyre, A., Tras la virtud (trad. de Valcárcel, A.), (Crítica, Barcelona 2004), pp. 204-205.

${ }^{9}$ La Revolución Francesa supuso la ruptura de la concepción política absolutista y con ella se consagró el modelo de Estado liberal, que se funda en la defensa de la libertad individual frente al Estado a través del reconocimiento claro del principio de legalidad. Desde esa concepción liberal, la pena como elemento pivotante del Derecho penal cumple una función utilitarista, influencia del contrato social Rousseauniano, a saber: protectora de la sociedad ante la existencia de hechos delictivos. En este momento histórico la pena era concebida desde esa funcionalidad retributiva, a la que precisamente se refirió KANT, I., Principios metafísicos del Derecho (trad. de Lizarraga, G.), (Victoriano Suárez, Madrid 1873), pp. 195-196. En el marco de la denominada teoría de la justa retribución, Kant sostenía que la pena cumplía dicha función retributiva respecto del delincuente, no respecto de la sociedad, de manera que la misma no podía responder a un fin preventivo, dado que, de ser así, el castigo al sujeto se efectuaría de manera absolutamente inconcebible en beneficio de la misma sociedad. Sin embargo, en el mundo globalizado actual en donde todo está interconectado, el imperativo moral supremo se convierte en el imperativo del saber: el mundo contemporáneo se ha vuelto tan completo que ello influye en la propia concepción liberal de la justicia. En la actualidad, la mayoría de las injusticias surgen de sesgos estructurales a gran escala que ya somos incapaces de detectar, dado que nuestra propia existencia depende de una enorme red de conexiones causales globales que se manifiestan en una vasta red de lazos económicos, políticos, etc., interconectados. 
voluntaria (de tipo contractual) que contraemos por consentimiento ${ }^{10}$. Sin embargo, ninguna de ellas explica la responsabilidad moral que los miembros de los clanes familiares adquieren por la conculcación de las tradiciones comunitarias de uno de sus parientes que desemboca en una ruptura de la armonía social que debe recomponer la justicia informal tradicional. Cabe concluir que, desde el punto de vista de la concepción teleológica de la persona, la formulación liberal de las obligaciones es demasiado superficial, ya que no puede explicar las responsabilidades morales que asumen las personas como miembros de una comunidad dada, y que no pueden explicarse refiriéndose a un contrato.

En consecuencia, para entender desde el punto de vista de la Filosofía moral los sistemas tradicionales de justicia informal hemos de concluir, siguiendo a Sandel ${ }^{11}$, que en ellos se verifica una tercera categoría de obligaciones morales: las de solidaridad o de adscripción; o, por mejor decir, obligaciones comunales. Al contrario de los deberes naturales, las obligaciones comunales son particulares, es decir no universales: comprenden las responsabilidades morales que los miembros de la comunidad tienen, no ante los seres racionales en cuanto tales, sino ante aquellos otros miembros de la comunidad a los que les unen unas tradiciones y costumbres comunes. Pero al contrario de las obligaciones voluntarias, no dependen de que se preste un consentimiento: su peso moral deriva, en cambio, de los aspectos de la reflexión moral que responden a la situación de que se reconozca que las tradiciones y costumbres se entrelazan con la vida de todos los miembros de la comunidad en donde el Tribunal informal tradicional ejerce su jurisdicción.

Debe agregarse, a renglón seguido, que lo que estas obligaciones de solidaridad comunales demandan debe complementar los derechos naturales o los Derechos Humanos, pero no rivalizar con ellos. Las obligaciones de solidaridad comunales resultan criticables sólo cuando conducen a la violación de un derecho natural. Por el contrario, si la concepción teleológica de las comunidades en donde ejercen su jurisdicción los sistemas tradicionales de justicia informal es correcta, las obligaciones de solidaridad comunales pueden ser más exigentes de lo que se desprende de la teoría liberal de la justicia, tanto que hasta rivalicen con los Derechos Humanos.

$\mathrm{Si}$, como sostenemos, la concepción teleológica de la capacidad de actuar en el orden moral ayuda a entender adecuadamente los sistemas sociales dominados por relaciones múltiples de la mayoría de las comunidades rurales de los cinco continentes en donde existen sistemas tradicionales de justicia informal, resulta razonable reconsiderar la manera de concebir la justicia propuesta por Aristóteles ${ }^{12}$. Si en estos contextos deliberar sobre lo que es bueno para una persona implica reflexionar sobre lo que es bueno para la armonía social de la comunidad a la que dicha persona pertenece, la aspiración a la neutralidad preconizada por las concepciones liberales de la justicia quizá sea un error si de lo que se trata, a la postre, es de plantear estrategias para introducir o fortalecer los principios del Estado de Derecho y promover los Derechos Humanos en los sistemas tradicionales de justicia informal.

En efecto, si analizamos los sistemas tradicionales de justicia informal desde la perspectiva de la virtud moral aristotélica podemos entender mejor su telos en las comunidades rurales dominadas

\footnotetext{
${ }^{10}$ Para una discusión más amplia sobre las implicaciones de la teoría liberal de la justicia seguimos a su mayor referente contemporáneo RAWLS, J., A Theory of Justice, (Harvard University Press, Cambridge 1971), pp. 108117.

11 Cfr. SAndel, M., Justicia ¿Hacemos lo que debemos? (trad. Campos Gómez, J. P.), 4. ${ }^{a}$ ed., (Debate, Barcelona 2017), p. 255.

${ }_{12}$ Para un análisis en profundidad sobre esta cuestión vid., por todos, GARCÍA SOTO, L., Teoría de la justicia e idea del Derecho en Aristóteles, (Marcial Pons, Madrid 2011), passim.
} 
por relaciones múltiples en donde existen. Con su actividad mediadora entre las partes en conflicto, los Tribunales informales tradicionales inculcan, no sólo a las partes en litigio sino también al resto de los miembros de la comunidad que participan activamente en el procedimiento informal, cuál debe ser la conducta virtuosa que han de adoptar (conforme a las tradicionales y al Derecho consuetudinario) para conseguir la restauración de la armonía de la comunidad. Además, la estrecha relación existente entre la ética de la responsabilidad colectiva y la ética de la vergüenza contribuye a que, con su sentencia, el Tribunal informal tradicional también ayude a las partes a adquirir la disposición de actuar virtuosamente.

Sin embargo, desde esta perspectiva no se puede pretender la aplicación estricta de los principios del Estado de Derecho a los sistemas tradicionales de justicia informal, porque un rasgo distintivo de la virtud moral aristotélica es precisamente que, aunque pueda conocerse la tradición o la costumbre aplicable, sin embargo, puede no saberse cómo o cuándo hay que aplicarla. Desde la perspectiva de la educación moral, los jueces informales deben discernir las características particulares de cada conflicto, la concreta situación de los sujetos enfrentados en litigio y los intereses de la comunidad en su conjunto para determinar si conviene aplicar una tradición en vez de otra costumbre: "ha de aceptarse previamente que todo tratamiento sobre la conducta debe expresarse mediante un bosquejo y no con exactitud. Lo mismo que también dijimos al principio que las explicaciones hay que exigirlas en razón de la materia; y los asuntos de la conducta y la conveniencia no tienen nada firme, como tampoco los de la salud (...) Pues no caen bajo ciencia alguna, ni tampoco bajo ninguna tradición oral, sino que los que obran deben, en cada caso, observar lo que conviene a la ocasión como pasa también en la Medicina y en la Náutica"13.

En consecuencia, los jueces informales están llamados a mediar entre las partes hasta hallar el justo medio aristotélico del conflicto que las enfrenta en litigio para poder dictar una sanción que condene a la persona debida, en la medida debida, por la razón debida y de la manera debida ${ }^{14}$, de tal manera que se reconcilie a las partes en conflicto y se restaure la armonía social en la comunidad.

Ahora bien, en la práctica siempre aparecen conflictos jurídicos potencialmente nuevos, y por ello los jueces informales deben saber qué tradición o costumbre es la apropiada dadas las circunstancias concurrentes en las partes en litigio y en la comunidad en general. Por esta razón, los jueces llamados a aplicar la justicia informal tradicional son designados en todo caso en atención a su auctoritas en la comunidad, porque la virtud moral requiere que el enjuiciamiento se realice conforme a la sabiduría práctica aristotélica ${ }^{15}$ : los jueces informales deben deliberar correctamente sobre lo que resulta apropiado, no sólo para las partes en conflicto, sino también para los miembros de la comunidad y para los seres humanos en general y, atendiendo a lo cambiante y a lo particular (para resolver el concreto conflicto surgido entre las partes), deben descubrir qué es lo mejor para reconciliar a las partes en conflicto y restaurar la armonía social en la comunidad dadas las circunstancias concurrentes ${ }^{16}$.

Por otra parte, cabe señalar que en todos los ejemplos de justicia informal tradicional existe un regustillo a justicia restaurativa, lo que también encaja con la teoría aristotélica de la justicia ${ }^{17}$. Al

\footnotetext{
${ }^{13}$ Cfr. Aristóteles, Ética a Nicómaco (trad. de Calvo Martínez, J. L.), (Alianza, Madrid 2001), p. 77.

14 Ibidem, pp. 91-92.

15 Ibidem, pp. 186-188.

16 Ibidem, pp. 189-191.

${ }^{17}$ De acuerdo con Hierro SánCHEZ-PeSCADOR, L. L., "El concepto de justicia y la teoría de los derechos", en Díaz García, E. y Colomer, J. L. (eds.), Estado, justicia, derechos, (Alianza, Madrid, 2002) p. 56, se puede sostener que para Aristóteles existen tres especies distintas de justicia particular: la distributiva (dianemetikón), la
} 
igual que ocurre en los sistemas tradicionales de justicia informal, la justicia restaurativa es un proceso mediante el cual todas las partes involucradas en una ofensa en particular se reúnen para resolver colectivamente cómo enfrentar las secuelas de la ofensa -con el reconocimiento y reparación del daño causado por el infractor y el perdón por parte de la víctima- y sus implicaciones para el futuro. Aunque, como también ocurre con los diversos sistemas de justicia informal, existe una enorme diversidad en las formas de la justicia restaurativa, todas ellas comparten el principio de la participación directa de las víctimas y los infractores: Las víctimas tienen la oportunidad de participar en el proceso de resolución, mientras que los infractores deben entender las consecuencias de sus acciones y el daño que han causado; se presta considerable atención al contexto en el que ocurre la ofensa; y el acuerdo que pone fin al conflicto pretende equilibrar las necesidades del infractor, de la víctima y de la comunidad.

Así, podemos concluir que los sistemas tradicionales de justicia informal suponen una tipología de justicia restaurativa a lo que cabe aplicar un razonamiento teleológico para entender su significado inmanente ${ }^{18}$. De hecho, en la década de 1960 en Nueva Zelanda se configuraron los denominados conferencing como modelo de justicia restaurativa a partir de algunos sistemas tradicionales de justicia informal presentes en el Pacífico sur, a través de los cuales se pretendía conciliar estas prácticas aborígenes con el interés de ofrecer una solución al conflicto que fuera positiva para la víctima y para el infractor ${ }^{19}$ : se trataba de vías que atendían a la manera de actuar y de

correctiva (diorthotikón) y la retributiva o conmutativa (antipeponthós). Sin embargo, se trata de una cuestión controvertida porque, como apunta EngLARD, I., Corrective and Distributive Justice. From Aristotle to Modern Times, (Oxford University Press, New York 2009), pp. 9-10, uno de los principales problemas se refiere a la relación exacta de la retribución (castigo) con las otras dos formas de justicia. De hecho, a lo largo de la historia se han propuesto varias soluciones conflictivas entre sí: (1) la retribución forma parte de la justicia distributiva; (2) es una parte de justicia correctiva; (3) es una tercera forma de justicia; (4) es una idea distinta que se puede aplicar a las otras dos formas básicas de justicia particular. Resulta curioso cómo la doctrina procesal también ha venido considerando que la justicia retributiva y la justicia restaurativa son ambas especies de la justicia distributiva, y ambas se proponen generalmente como maneras de reconocer inteligiblemente el significado moral de la autonomía individual, lo que lleva a considerar que mediante ellas se restaura la distribución de los derechos existentes antes de que se produzcan los hechos, tanto como sea posible. Cfr., en este sentido, WATSON, D., Boucherat, J., y Davis, G., "Reparation for retributivists", en Wright, M. y Galaway, B. (ed.), Mediation and Criminal Justice: victims, offenders and community, (Sage, London 1999) p. 220. La consecuencia de todo ello es clara: nibil novum sub sole!

18 Resulta clarificador el propio Aristóteles cuando sostiene que "la justicia rectificativa sería el término medio entre pérdida y ganancia. Por ello, también, cuando disputan los hombres recurren al juez: y dirigirse al juez es dirigirse a lo justo, pues el juez pretende ser como la justicia dotada de vida. Y buscan que el juez sea medio y algunos los llaman "mediadores", como si alcanzaran el medio cuando obtienen justicia. Luego la justicia es un cierto medio si también lo es el juez. Y el juez iguala, y, como si se tratara de una línea que está dividida en partes desiguales, él quita aquello en lo que el segmento mayor excede a la mitad y se lo añade al segmento menor. Cuando un todo se divide en dos, las gentes dicen que tienen lo suyo precisamente cuando toman la parte igual" (Cfr. Ética a Nicómaco, op. cit., p. 161).

${ }^{19}$ Resultan muy ilustrativas de la vinculación existente entre los sistemas tradicionales de justicia informal y los modernos sistemas alternativos de resolución de conflictos las palabras de MCELREA, F., "Justice in the Community: The New Zealand Experience", en BURNSIDE, J. y BAKER, N. (eds.), Relational Justice: Repairing the Breach, (Waterside Press, Winchester 1994) pp. 94-95, cuando sostiene que "es significativo que un Comité del Parlamento de Nueva Zelanda viajara entre febrero y abril de 1988 a los lugares de reunión de los maoríes por las islas del Pacífico de todo el país, escuchando las propuestas aborígenes sobre cómo refundir el proyecto de ley para hacerlo más culturalmente relevante para la población polinesia y cómo diseñar un procedimiento más simple y menos burocrático. Creo que el mecanismo [de justicia restaurativa denominado] Family Group Conference resultado de esos trabajos parlamentarios es el descendiente directo del sistema [tradicional de justicia informal] whanau, largamente empleado por los maoríes, aunque está modificado para adaptarse a su nuevo contexto, por ejemplo, con la inclusión de la policía". En fin, para un análisis in extenso del sistema tradicional 
ser de estas comunidades específicas y que, precisamente por el rechazo de los mismos al sistema de justicia formal estatal, implicaban unas mayores probabilidades de integración de estos colectivos en la sociedad ${ }^{20}$.

En consecuencia, la concepción teleológica que impera en los sistemas tradicionales de justicia informal, y las bondades de las obligaciones morales de solidaridad comunal que los sustentan, han sido incorporadas en los ordenamientos jurídicos occidentales contemporáneos a través de la filosofía de la justicia restaurativa ${ }^{21}$. Por este motivo, los sistemas tradicionales de justicia informal pueden incorporarse a los ordenamientos jurídicos contemporáneos de corte occidental como un sistema complementario de Administración de Justicia más, en pie de igualdad con la conciliación, la mediación y el arbitraje que tanta importancia han cobrado en los últimos treinta años en los ordenamientos jurídicos contemporáneos como sistemas alternativos de resolución de conflictos 22 .

de justicia informal maorí W aitangi, que se rige por los principios de "centralidad de las relaciones comunitarias" o whanaungatanga, "autoridad espiritual para sancionar" o mana, "reconocimiento de la dimensión espiritual" o tapu/noa y reciprocidad o utu, vid., por todos, JONES, C., "Maori and State visions of Law and peace", en HiCkford, M. y JONes, C. (eds.), Indigenous Peoples and the Law. International perspectives on the Treaty of Waitangi, (Routledge, Oxford 2018) pp. 18-43.

${ }^{20}$ Cabe recordar que también a finales de la década de los años sesenta y principios de la década de los años setenta del siglo XX se produce un importante impulso de la justicia restaurativa en los Estados Unidos de América. Resulta interesante señalar que en los Estados unidos de América determinadas comunidades, como sucedió en las comunidades menotinas - caracterizadas por establecerse donde sus tradiciones y prácticas centenarias (una rama pacifista y trinitaria del movimiento cristiano anabaptista originado en el siglo XVI, cuya lengua es el Deitsch) se acepten sin interferencia del Estado y de la sociedad moderna-, potenciaron la justicia restaurativa, ya que participaban de los principios de la justicia reparadora en su planteamiento vital, y en el fondo se trataba de considerar que es mejor resolver los conflictos y plantear colectivamente los comportamiento anti-grupo para establecer también en el marco de la comunidad la respuesta ante dichas conductas no deseables, que someterse a un poder exógeno, ajeno, extraño y al que no se le otorgaba ningún grado de legitimidad. La sociedad norteamericana de las décadas sesenta y setenta del pasado siglo favoreció estas corrientes ideológicas, que marcaron un importante hito en el desarrollo y consolidación de posiciones jurídicas que alteraron algunas de las bases de la justicia liberal imperante, fundamentalmente por la consagración de una ideología antisistema basada en la libertad, la paz, la colectividad o el sentimiento social propio de lo que se denomina el movimiento hippie. Así se generó el movimiento ideológico que, tras sus influencias filosóficas, dio lugar a las Alternative Dispute Resolution, que revitalizaron en la principal potencia mundial la justicia restaurativa. A partir de ahí no cesó de expandirse, primero en los países pertenecientes al modelo del common law (Australia, Canadá, Inglaterra y Gales), y posteriormente a Alemania, Francia, Noruega y Finlandia para que, tras reconocerse su importancia como sistema alternativo a la justicia formal, se incorporara en el ordenamiento comunitario europeo y, a su través, se haya transpuesto en todos los ordenamientos jurídicos europeos. Cfr. Barona Vilar, S., Mediación Penal. Fundamento, fines y régimen jurídico, (Tirant lo Blanch, Valencia 2011), pp. 121-131.

${ }^{21}$ Sherman, L. W. y STRAng, H., Restorative justice: the evidence, (The Smith Institute, London 2007) p. 13, han sostenido la bondad de la justicia restaurativa por dos tipos de razones: por un lado, procedimentalmente encuentra una vía más humana y respetuosa de las víctimas y de los infractores que la justicia formal; por otro lado, su efectividad se halla en los resultados alcanzados, que responden a menor reiteración delictiva, más reparación de las víctimas, menos delitos cometidos por venganza de las víctimas y más reconciliación y vinculación afectiva familiar y con los miembros de la comunidad

22 Desde el punto de vista ontológico, la diferencia entre los sistemas tradicionales de justicia informal y los sistemas alternativos de resolución de conflictos (conciliación, mediación y arbitraje) estriba en que los primeros se fundamentan en las obligaciones de solidaridad comunales que, como se ha sostenido, no requieren un consentimiento formal sino que se producen entre aquellos miembros de la comunidad a los que les unen unas tradiciones y costumbres comunes: su peso moral deriva, por tanto, de los aspectos de la reflexión moral que responde a la situación de que se reconozca que las tradiciones y costumbres se entrelazan con la vida de todos los miembros de la comunidad en donde el Tribunal informal tradicional ejerce su jurisdicción; mientras que la fundamentación moral de los sistemas alternativos de resolución de conflictos como la conciliación, la 
La incorporación de la perspectiva moral aristotélica, lejos de suponer una confusión entre Derecho y moral, supone la introducción de una concepción humanista en la justicia, que resulta complementaria a la justicia retributiva liberal, y que de hecho supone reconocer (y, en su caso, garantizar) el acceso a la justicia de millones de personas en todo el mundo, que la obtienen casi exclusivamente de los sistemas tradicionales de justicia informal.

\section{Justicia informal tradicional, Estado de Derecho y Derechos Humanos}

Muchos sistemas tradiciones de justicia informal no respetan los principios configuradores del Estado de Derecho y/o violan los Derechos Humanos.

Es cierto que, desde la perspectiva moral aristotélica, no se puede pretender la aplicación estricta de los principios del Estado de Derecho a los sistemas tradicionales de justicia informal. Sin embargo, como ocurre con el Tribunal de las Aguas de Valencia, sí que podemos pretender que los sistemas tradicionales de justicia informal pueden estar sometidos matizadamente al imperio de la ley, modulando los principios que rigen el Estado de Derecho en función de sus respectivas tradiciones y Derechos consuetudinarios, y de la sabiduría práctica con la que la justicia informal tradicional está llamada a mediar entre las partes para encontrar el justo medio que ponga fin al conflicto, reconcilie a las partes en litigio y restaure la armonía social en la comunidad. Para conseguir que los sistemas tradicionales de justicia informal actúen sometidos al imperio de la ley, y se rijan conforme a una modulación de los principios nucleares del Estado de Derecho pueden aplicarse determinados criterios de complementariedad entre los sistemas tradicionales de justicia informal y los sistemas juridiciales estatales, que hemos tenido la oportunidad de analizar detenidamente en otro lugar ${ }^{23}$.

También resulta evidente que en el siglo XXI no cabe el reconocimiento de sistemas tradicionales de justicia informal que violen los Derechos Humanos. Bien es cierto que muchas tradiciones y costumbres ancestrales han sido adaptadas motu proprio por las comunidades aborígenes a la realidad social vigente, de tal forma que en la actualidad cumplen los estándares mínimos del Derecho Internacional de los Derechos Humanos. El supuesto más claro es el de la justicia especial indígena colombiana que está reconocida constitucionalmente, de tal manera que se autoriza a las autoridades de los pueblos indígenas el ejercicio de funciones jurisdiccionales dentro de su ámbito territorial, y de conformidad con sus propias normas y procedimientos, siempre y cuando no sean contrarios a la Constitución y a la legislación colombiana; de tal forma que, a través de un sistema de recursos sobre las resoluciones dictadas por los sistemas tradicionales de justicia informal colombianos - diseñados como cauce procesal para la coordinación de la jurisdicción indígena con el sistema judicial colombiano-, se garantiza que esta justicia informal tradicional indígena cumple con los estándares de Derecho Internacional de los Derechos Humanos de los que la República de Colombia es parte ${ }^{24}$.

mediación y el arbitraje se encuentra en obligaciones voluntarias que, a modo de contrato, requieren el consentimiento expreso de las partes.

23 Cfr. LiÉBAnA OrTiz, J. R., op. cit. pp. 137-140.

${ }^{24}$ En este sentido puede mencionarse, por ejemplo, cómo la Corte Constitucional de Colombia ha interpretado la pena de fuete que impone como sanción la jurisdicción paez como una flagelación que inflige un daño corporal mínimo, que no reviste los niveles de gravedad para que pueda considerarse como tortura ni conforme a la legislación nacional colombiana ni conforme a ningún Tratado de Derecho Internacional para la erradicación de la tortura, y que tiene más bien un carácter simbólico o ritual para devolver la armonía a la comunidad. 
Sin embargo, no es menos cierto que existen otros sistemas tradicionales de justicia informal que continúan violando los Derechos Humanos con la aplicación de sus tradiciones y costumbres ancestrales, especialmente de los miembros más débiles de la comunidad (mujeres, niños, personas en situación de pobreza, minorías étnicas o religiosas), sobre los que existe un consenso generalizado en que la simple prohibición de dichas prácticas es la forma menos efectiva de reformar dichos sistemas tradicionales de justicia informal para que cumplan con los estándares mínimos de Derechos Humanos.

En estos casos resulta necesario realizar planteamientos de estrategias para introducir o fortalecer los principios del Estado de Derecho y promover los Derechos Humanos en las prácticas informales tradicionales y en las tradiciones y costumbres ancestrales. Para ello es necesario que, con carácter previo a cualquier acción legislativa, el Estado -o las Organizaciones No Gubernamentales de Derechos Humanos que operen en la región en el caso de tratarse de Estados débiles o fallidoslleven a cabo una labor de concienciación de la población que habita en las zonas en donde se aplica esta justicia informal tradicional. Una de las características del Derecho consuetudinario es su flexibilidad, por lo que resulta factible que se lleve a cabo una labor pedagógica tanto de los jueces informales como de los miembros de las comunidades rurales, especialmente de los más débiles dentro de ellas ${ }^{25}$. En este sentido, resulta especialmente interesante que los Estados, o las Organizaciones No Gubernamentales de Derechos Humanos que operen en estas regiones, desarrollen proyectos de formación dirigidos específicamente al empoderamiento de las mujeres y los grupos étnicos y religiosos minoritarios para que también conozcan sus derechos y los ejerciten activamente dentro de los sistemas tradicionales de justicia informal o bien, en su caso, directamente en el sistema jurisdiccional estatal.

Igualmente, para una efectiva promoción de los Derechos Humanos en los sistemas tradicionales de justicia informal resulta vital que los jueces informales, es decir los miembros prominentes de las comunidades rurales, se conciencien realmente de la necesidad de proteger los Derechos Humanos de los miembros de su comunidad, lo que puede lograrse no sólo con programas de concienciación específicos para ellos, sino también intentado que se reconozca auctoritas a determinados funcionarios estatales que sean miembros de la comunidad, para que también se les designe como jueces informales.

Sólo cuando se haya concienciado a todos los miembros de la comunidad de las bondades de adaptar sus tradiciones y costumbres ancestrales para proteger los Derechos Humanos en cuanto deberes morales naturales, será posible introducir las reformas legales pertinentes que permitan aplicar los criterios de complementariedad entre los sistemas tradicionales de justicia informal y los sistemas juridiciales estatales, para posteriormente introducir un sistema de recursos sobre las resoluciones dictadas por dichos sistemas tradicionales de justicia informal; segunda instancia procesal diseñada para la coordinación de la jurisdicción informal tradicional con el sistema jurisdiccional estatal que contribuya a garantizar que la justicia informal tradicional cumple con los principios esenciales del Estado de Derecho y con los estándares de Derecho Internacional de los Derechos Humanos.

\footnotetext{
${ }^{25}$ Más allá de proclamas retóricas sobre la importancia de cumplir con los estándares mínimos del Derecho Internacional de los Derechos Humanos y las bondades de su aplicación universal, la concienciación tanto de las élites como de los miembros de las comunidades rurales donde extienden su jurisdicción los sistemas tradicionales de justicia informal debe adoptar también una perspectiva filosófica: se trata en definitiva del cumplimiento de deberes morales universales ante los seres humanos en cuanto seres racionales.
} 


\section{Referencias}

ARISTÓTeles, Ética a Nicómaco (trad. de Calvo Martínez, J. L.), (Alianza, Madrid 2001)

Barona Vilar, S., Mediación Penal. Fundamento, finesy régimen juridico, (Tirant lo Blanch, Valencia 2011).

Chirayath, L., Sage, C. y Woolcock, M, Customary Law and Policy Reform: Engaging with the Plurality of Justice Systems, (World Bank, Washington 2005)

Danish Institute for Human Rights, Informal Justice Systems: Charting a Course for Human Rights Based Engagement, (United Nations Entity for Gender Equality and the Empowerment of Women, New York 2013).

García Soto, L., Teoría de la justicia e idea del Derecho en Aristóteles, (Marcial Pons, Madrid 2011).

HierRo SÁnChEZ-PESCADOR, L. L., "El concepto de justicia y la teoría de los derechos", en DíAZ García, E. y COLOMER, J. L. (eds.), Estado, justicia, derechos, (Alianza, Madrid, 2002), pp. 11 74.

JONES, C., "Maori and State visions of Law and peace", en HiCKFORD, M. y JONES, C. (eds.), Indigenous Peoples and the Law. International perspectives on the Treaty of Waitangi, (Routledge, Oxford 2018) pp. 18-43.

Kant, I., Principios metafísicos del Derecho (trad. de Lizarraga, G.), (Victoriano Suárez, Madrid 1873)

LIÉBANA ORTIZ, J. R., Los sistemas tradicionales de justicia informal en el siglo XXI, (Thomson Reuter Civitas, Cizur Menor 2018)

MacIntyre, A., Tras la virtud (trad. de Valcárcel, A.), (Crítica, Barcelona 2004).

MCElREA, F., "Justice in the Community: The New Zealand Experience", en BURNSIDE, J. y BAKER, N. (eds.), Relational Justice: Repairing the Breach, (Waterside Press, Winchester 1994).

RAWLS, J., A Theory of Justice, (Harvard University Press, Cambridge 1971).

SANDEL, M., Justicia ¿Hacemos lo que debemos? (trad. Campos Gómez, J. P.), 4. ${ }^{a}$ ed., (Debate, Barcelona 2017).

SHERMAN, L. W. y STRANG, H., Restorative justice: the evidence, (The Smith Institute, London 2007).

ROUSSEAU, J. J., Discurso sobre la economía política (trad. y ed. Vélez, F.), (Maia, Madrid 2011).

Walzer, M., Spheres of Justice, (Basic Books, New York 1983).

Watson, D., Boucherat, J., y Davis, G., "Reparation for retributivists", en Wright, M. y GALAWAY, B. (ed.), Mediation and Criminal Justice: victims, offenders and community, (Sage, London 1999), pp. 212-228. 